\title{
Soil Salinity Detection in Semi-Arid Region Using Spectral Unmixing, Remote Sensing and Ground Truth Measurements
}

\author{
Moncef Bouaziz $^{1,2}$, Sarra Hihi' ${ }^{1}$, Mahmoud Yassine Chtourou${ }^{1}$, Babatunde Osunmadewa ${ }^{2}$ \\ ${ }^{1}$ University of Sfax, National Engineering School of Sfax, 3E Laboratory, Sfax, Tunisia \\ ${ }^{2}$ Faculty of Environmental Sciences, Institute of Remote Sensing, TU-Dresden, Helmholtzstr, Dresden, Germany \\ Email: Moncef.bouaziz@gmail.com
}

How to cite this paper: Bouaziz, M., Hihi, S., Chtourou, M.Y. and Osunmadewa, B. (2020) Soil Salinity Detection in Semi-Arid Region Using Spectral Unmixing, Remote Sensing and Ground Truth Measurements. Journal of Geographic Information System, 12, 372-386.

https://doi.org/10.4236/igis.2020.124023

Received: February 15, 2020

Accepted: August 28, 2020

Published: August 31, 2020

Copyright $\odot 2020$ by author(s) and Scientific Research Publishing Inc. This work is licensed under the Creative Commons Attribution International License (CC BY 4.0).

http://creativecommons.org/licenses/by/4.0/

\section{(c) (i) Open Access}

\begin{abstract}
Soil salinity is one of the serious environmental problems ravaging the soils of arid and semi-arid region, thereby affecting crop productivity, livestock, increase level of poverty and land degradation. Hyperspectral remote sensing is one of the important techniques to monitor, analyze and estimate the extent and severity of soil salt at regional to local scale. In this study we develop a model for the detection of salt-affected soils in arid and semi-arid regions and in our case it's Ghannouch, Gabes. We used fourteen spectral indices and six spectral bands extracted from the Hyperion data. Linear Spectral Unmixing technique (LSU) was used in this study to improve the correlation between electrical conductivity and spectral indices and then improve the prediction of soil salinity as well as the reliability of the model. To build the model a multiple linear regression analysis was applied using the best correlated indices. The standard error of the estimate is about $1.57 \mathrm{mS} / \mathrm{cm}$. The results of this study show that hyperion data is accurate and suitable for differentiating between categories of salt affected soils. The generated model can be used for management strategies in the future.
\end{abstract}

\section{Keywords}

Hyperion, Linear Spectral Unmixing (LSU), Spectral Indices, Ground-Truth, Soil Salinity, Gabes

\section{Introduction}

Soil degradation as a result of increased accumulation of salt content in the soil is one of the major environmental problems in arid and semi-arid region of the world ([1] [2]). The impact of soil salinity is mostly adverse especially in agri- 
cultural lands thereby causing huge agricultural loss [3] and low standard of living for local inhabitants whose means of sustenance (livelihood) is mainly dependent on farming activities ([4] [5]). Apart from human-induced salinization caused by improper irrigation practices and poor drainage system ([6] [7] [8]), climatic factor such as low precipitation exacerbate soil salinity ([9]-[15]). The phenomenon of salinization is more and more worrying. Although estimates of salinity differ from one author to another, the areas affected are generally estimated at one billion hectares, which represents $7 \%$ of the total surface area of the continents [16], 77 million hectares are saline soils induced by human activity, $58 \%$ in irrigated areas [17]. Tunisia, an example of a country from arid to semi-arid climate, is also exposed by soil salinization; about $10 \%$ of Tunisia's areas are already affected by salinization in varying degrees ([18] [19]).

Although several methods have been used by many researchers to assess soil salinity in the semi-arid region of Tunisia such as the study of ([20] [21] [22] [23]), some of this studies are based on in-situ measurement and laboratory analysis, which makes study on spatial and temporal monitoring of the extent and severity of soil salinity imperative in order to take protective measures against further deterioration of the soil.

Other authors used traditional methods to assess, monitor and predict soil salinity, however, this method of salinization assessment is laborious and limited to small sample areas, thus making it not representative for large areas ([9] [19] [24]). Owing to the complexity of monitoring soil salinity using traditional method, remote sensing data (multispectral and hyperspectral data) coupled with geo-statistical techniques have proved to be an appropriate method for monitoring soil salinity at different spatial and temporal resolution from national to regional scale ([1] [4] [25]). Many authors demonstrated the utility of combining remote sensing data with ground-truth measurements to detect soil salinity ([26] [27] [28] [29]). Linear Spectral Unmixing (LSU) method is one of the most reliable techniques to monitor soil salinity ([30] [31]). Linear Spectral Unmixing is used to estimate the abundance fractions of materials present in an image pixel (using endmembers) to finally elaborate abundance maps that are going to be very useful in the rest of the work.

In order to fill the gap in knowledge, the present work aims to valorise the techniques used in the field of remote sensing to detect areas affected by soil salinization in the arid and semi-arid zones of Tunisia specifically in the region of Ghannouch, Gabes. Our goal is to combine in-situ measurement with remotely sensed data (hyperspectral satellite image) in order to better understand the severity of soil salinization using integrated approach capable of delineating and mapping affected areas for proper land management, so as to ensure that such fragile ecosystem is not completely degraded in the future.

\section{Materials and Methods}

\subsection{Investigation Area}

Ghannouch, Gabes lies between Mediterranean and Saharan region. It is located 
in the South-East of Tunisia and falls within Latitude $33^{\circ} 56^{\prime}$ and Longitude $10^{\circ} 03^{\prime}$ as shown in Figure 1. The study area was chosen because of its important agricultural interests in this region, and the environmental problems related to soil, such as salinization. Geomorphologically, the study area belongs to the plain of Jeffara and more precisely to Jeffara coast (Gulf of Gabes) [33]. Ghannouch, Gabes, by its maritime position and its opening on the Mediterranean, is characterized by an arid climate. There is virtually no rainfall all year long. This climate is considered to be BWh by the Köppen-Geiger climate classification (B refers to a dry climate where annual evaporation exceeds annual precipitation, $\mathrm{W}$ means a desert climate and annual precipitation $<50 \%$ of the threshold, h: a dry, hot climate with an average annual temperature $>18^{\circ} \mathrm{C}$ ). The average temperature in Ghannouch is $19.3^{\circ} \mathrm{C}$, while August is the hottest month of the year with mean annual temperature of $27.6^{\circ} \mathrm{C}$. The mean annual rainfall is $176 \mathrm{~mm}$, while January is the coldest month of the year, the average temperature in January is $10.9^{\circ} \mathrm{C}$. Evaporation in this region is relatively very high (between 1500 $\mathrm{mm}$ to $2000 \mathrm{~mm}$ ) due to the dry climate conditions [33]. Therefore, the salt that is left after water evaporation on the top soils accumulates rapidly and accelerates soil salinization process. This fact leads to salt accumulation in the upper layers of the Chottsediments and to crust formation [34].

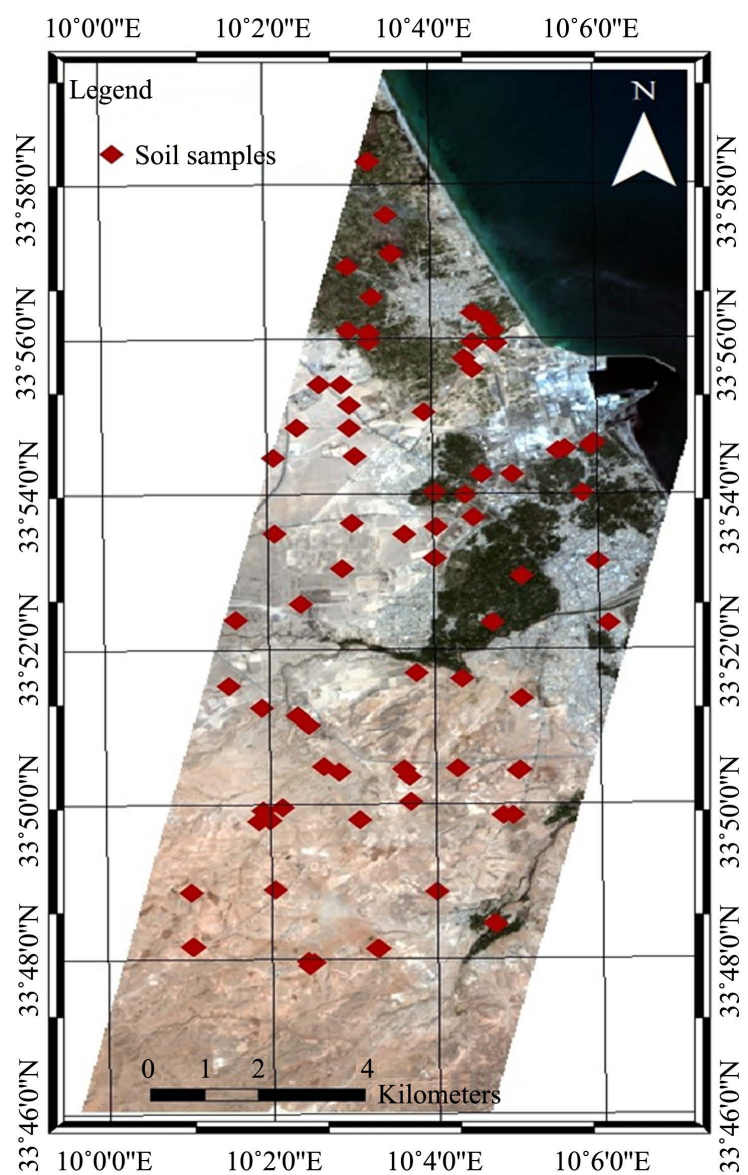

Figure 1. Location of the study area, Hyperion image of Gabes, Tunisia 2010. 


\subsection{Data Pre-Processing}

To build the model we used 14 spectral indices (these indices were generated from different remote sensing indicators (intensity, colour, salinity) as shown in Table 1, spectral bands from Hyperion data and ground truth measurements of 102 samples (EC measurements) which reveal the quantity of salt in the top layer of soil (0 to $10 \mathrm{~cm}$ depth).

\section{Hyperion Data}

The Hyperion is a high-resolution hyperspectral imaging instrument. The Hyperion images the earth's surface in 240 contiguous spectral bands with high radiometric accuracy, covering the region from $400 \mathrm{~nm}$ to $2.5 \mu \mathrm{m}$, at a spatial resolution of $30 \mathrm{~m}$. The hyperspectral imagery provides opportunities to extract more detailed information than is possible using traditional multispectral data [35]. The importance of hyperspectral data in various studies as mentioned by [36] makes it suitable for soil salt content monitoring in semi-arid region.

Table 1. Soil salinity indices based on different band ratios.

\begin{tabular}{|c|c|c|}
\hline Spectral indices & Equation & References \\
\hline BI: Brightness index & $\frac{\sqrt{B^{2}+G^{2}+R^{2}}}{\sqrt{3}}$ & ZhuoLuoa et al., 2008 \\
\hline Int1: intensity within the visible spectral range & $\frac{G+R}{2}$ & Douaoui et al., 2006 \\
\hline Int2: intensity within the VIS-NIR spectral range & $\frac{G+R+N I R}{2}$ & Douaoui et al., 2006 \\
\hline CI: Color index & $\frac{R-G}{R+G}$ & ZhuoLuoa et al., 2008 \\
\hline HI: Hue index & $\frac{2 R-G-B}{G-B}$ & ZhuoLuoa et al., 2008 \\
\hline RI: Redness index & $\frac{R^{2}}{B+G^{2}}$ & ZhuoLuoa et al., 2008 \\
\hline SI1: salinity index 1 & $\sqrt{B * R}$ & Khan et al., 2005 \\
\hline SI2: salinity index 2 & $\sqrt{G * R}$ & Khan et al., 2005 \\
\hline SI3: salinity index 3 & $\sqrt{G^{2}+R^{2}+N I R^{2}}$ & Douaoui et al., 2006 \\
\hline SI4: salinity index 4 & $\sqrt{G^{2}+R^{2}}$ & Douaoui et al., 2006 \\
\hline SI5: salinity index 5 & $\frac{B}{R}$ & Bannari et al., 2008 \\
\hline S I9: salinity index 9 & $\frac{N I R-R}{G}$ & Abass and Khan, 2007 \\
\hline SI-11: salinity index 11 & $\frac{S W I R 1}{S W I R 2}$ & Bannari et al., 2008 \\
\hline ASTER_SI: salinity index ASTER & $\frac{S W I R 1-S W I R 2}{S W I R 1+S W I R 2}$ & Bannari et al., 2008 \\
\hline
\end{tabular}




\subsection{Proposed Integrated Approach}

Taking into consideration the complexity of salinization process, identification of salt affected regions remains challenging. Our approach exposes an attempt to predict salt affected areas in the South-East of Tunisia through several remote sensing and geo-statistical techniques.

The flow chart in Figure 2 is a simplified description of the succession steps followed in this research.

Soil samples were collected in May and June 2010, which corresponds to the hyperspectral data acquisition date. The choice of the dry season to collect the samples was aimed at enhancing the detection of spectral characteristics of salt at the surface during salt accumulation at that specific time since soil salt rises in dry season due to capillarity. All the samples used in this study were token at least $30 \mathrm{~m}$ away from objects, which are not defined as soil (e.g.: trees, houses, streets, etc.) to minimize any noise that could affect the spectral signature.

At all sample locations, a specific procedure was used to collect the soil. Each analysed sample of this work is a mix of four soil samples. These 4 samples are collected from 4 corners of a $(30 \times 30)$ square, where the center is considered the location of the sample Figure 3). The mix of 4 soil samples collected from 4 corners of the square is the soil sample considered for chemical analysis Figure 4. These steps were applied for all samples, in order to optimize the representation of the samples within the pixel of the Hyperion image [37].

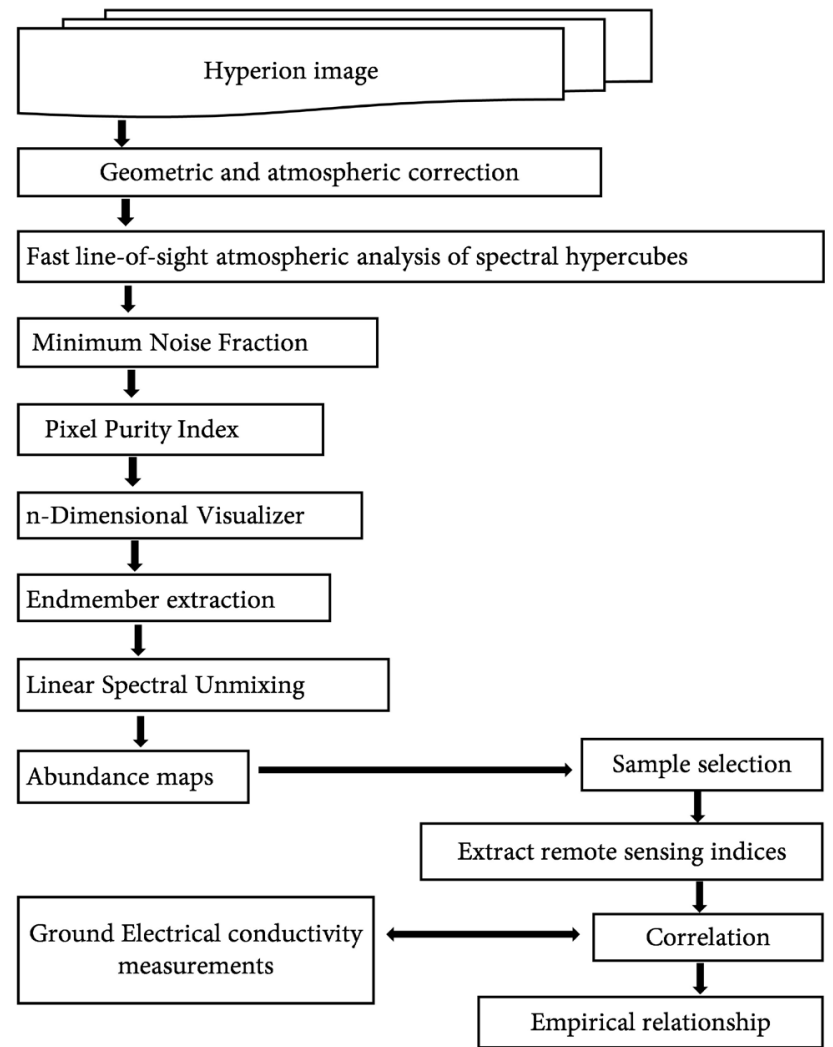

Figure 2. Simplified flow diagram of the spatial estimation approach. 


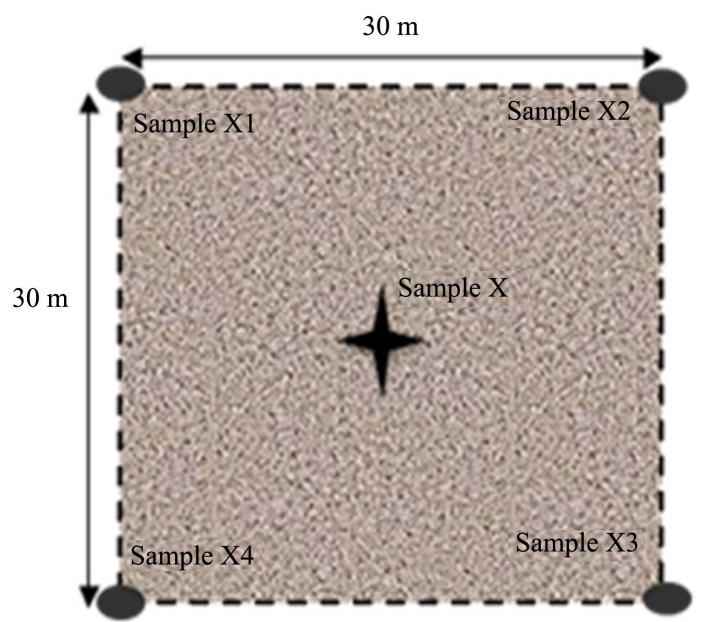

Figure 3. Soil sampling method.

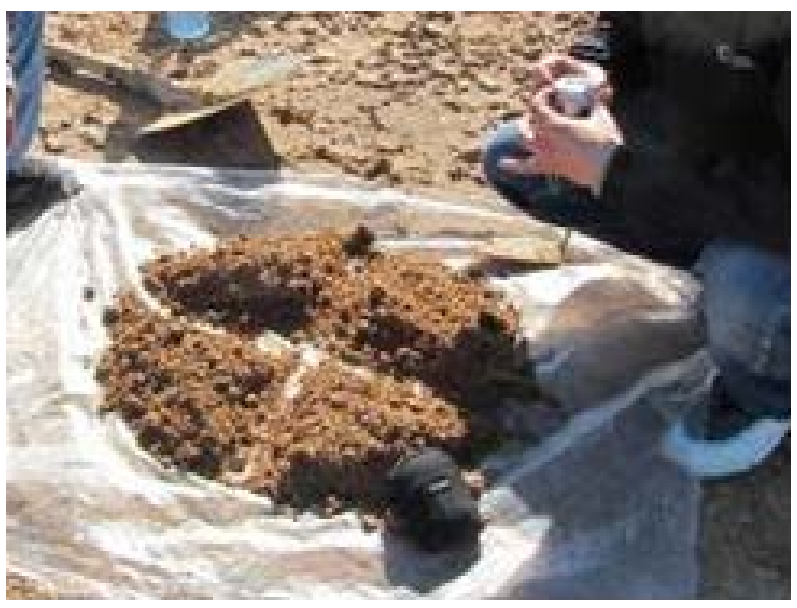

Figure 4. Mixing of the samples from the 4 corners to represent one soil sample.

Salinity at the topsoil is determined by measuring electrical conductivity (EC). $1 / 5$ soil/water diluted extracts is a convenient method used in this study to estimate soil salt content. To measure the EC of our samples, following steps are conducted: 1) Drying the samples, 2) Sieving (Size of the soil particle $<2 \mathrm{~mm}$ ), 3) Agitation, 4) Measure the $\mathrm{pH}$ and then after a rest of $30 \mathrm{~min}$ the $\mathrm{EC}$ value. EC is usually expressed in decisemens per meter at $25^{\circ} \mathrm{C}(\mathrm{dS} / \mathrm{m})$.

We used twenty indices with the Hyperion data to map salt affected soil. We used a Pearson correlation between the remote sensing indices and the electrical conductivity measurements from the field to assess the efficiency of each index in characterising soil salinity. The LSU method was applied to determine the abundance of materials in the hyperspectral image based on three abundance maps (vegetation, soil and urbanism). LSU is used to distinguish if the pixel of each sample is representative for the soil or not. We explored all the pixels representing the location of the samples and then, we considered only the pixels incorporating more than $50 \%$ of soil (computed from the abundance maps, as explained in the results Section 3.1). This step was made only to make sure that 
the spectral signature from the sample is emitted mainly from soil. Subsequently, the correlations between the EC and the remote sensing indices are recomputed. The impact of the LSU method is discussed in Section 3.1. Multiple Linear Regressions (MLR) is a multivariate statistical technique and one of the most widely used techniques to determine the correlation between a response variable and some combination of two or more predictor variables. Several multiple linear regressions (MLR's) are explored in this study to predict soil salinity. All the statistical operations (computing of correlation, conducting of MLR and random sample selection) were done using XISTAT software.

\subsubsection{Hyperion Data and Its Preprocessing}

The Hyperion data contain a spectral range of $356-2576 \mathrm{~nm}$ at $10 \mathrm{~nm}$ bandwidth. The Level-1 radiometric product used in the study has 242 bands; out of them only 198 are calibrated, i.e. band 8 to 57 for visible-to-near-infrared (VNIR) and 77 to 224 on shortwave-infrared (SWIR) regions. The overlap between the focal planes of VNIR and SWIR makes only 196 unique channels available. Few bands with unacceptable noise and streaking along with bands between 1400 and $1900 \mathrm{~nm}$ with high water absorption were removed from the further processing. Hence, 178 bands from the 196 unique bands were selected. In order to retrieve the surface reflectance by eliminating the atmospheric components, atmospheric correction was carried out by using ENVI's fast line-of-sight atmospheric analysis of spectral hypercubes (FLAASH) module. Necessary parameters for the FLAASH were determined by the metadata of the image files. In FLAASH module, the atmospheric model was selected as "Mid-Latitude Summer", whereas "Rural" was used as aerosol model. The dimension reduction of the atmospherically corrected Hyperion data was carried out using Minimum Noise Fraction (MNF) technique [38]. The MNF function identifies the noises and then allows the band classification. The MNF output images contain steadily decreasing image quality. Based on the eigenvalues, first thirteen bands of the 178 MNF bands were selected, the remaining bands with low $(<1)$ eigenvalues were eliminated from further processing. The selected bands were inversed to reconstruct the MNF-corrected Hyperion data. The atmospheric corrected Hyperion data with reduced dimensionality was used for further utilization.

\subsubsection{Endmember Extraction}

The Endmember extraction is one of the most fundamental and crucial tasks in hyperspectral data exploitation and an ultimate goal of an endmember extraction is to find the purest pixel. In this study we used Pixel Purity Index (PPI) function on selected MNF bands to identify the most spectrally pure pixels in our hyperspectral data. PPI is computed by projecting n-D scatter plots on a random unit vector. The n-D Visualizer is used then to locate, identify, and cluster the purest pixels and the most extreme endmembers in a dataset in $\mathrm{n}$-dimensional space and from there we extract our endmembers. 


\subsubsection{LSU Technique}

Linear spectral mixture analysis (LSMA) is a widely used technique in remote sensing to estimate abundance fractions of materials present in an image pixel. In order for an LSMA-based estimator to produce accurate amounts of material abundance, it generally requires two constraints imposed on the linear mixture model used in LSMA, which are the abundance sum-to-one constraint and the abundance no negativity constraint. The first constraint requires the sum of the abundance fractions of materials present in an image pixel to be one and the second imposes a constraint that these abundance fractions be nonnegative. While the first constraint is easy to deal with, the second constraint is difficult to implement since it results in a set of inequalities and can only be solved by numerical methods. Consequently, most LSMA-based methods are unconstrained and produce solutions that do not necessarily reflect the true abundance fractions of materials. In this case, they can only be used for the purposes of material detection, discrimination, and classification, but not for material quantification [39].

The detected signal is always a combination of signals produced by the different types covered by the pixel, that's why we used LSU method to identify the number of endmembers and then estimate the abundance fractions of materials present in a pixel as shown in Figure 5.

\section{Results and Discussion}

\subsection{Spectral Characteristics of Ground Features}

Figure 6 shows the spectral behaviour of salt-affected soil in Gabes, Ghannouch of 4 samples with varying EC measurements. Visible, near-infrared (NIR) and shortwave infrared (SWIR) are the investigated spectral regions provided by the Hyperion data. Reflectance profiles from Figure 6 show a ranking of the salinity classes. Within the visible and NIR-range, the four samples represented in Figure 6 show a good distinction between the different categories of salt-affected soils from the Hyperion data. Reflectance in all intervals shows that slightly saline soil (low electrical conductivity) have higher spectral response than salt-affected soils (high electrical conductivity).

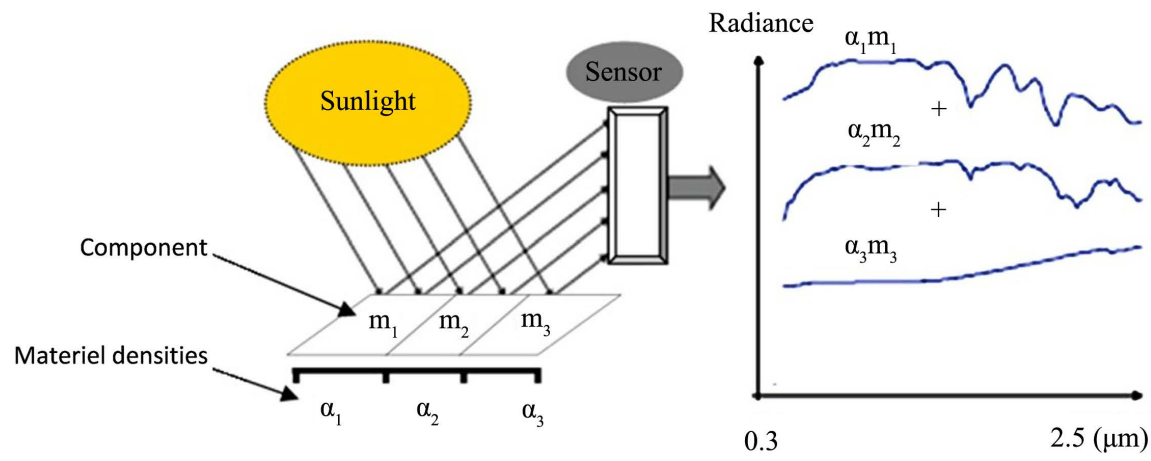

Figure 5. Linear unmixing process (Bioucas-Dias and Figueiredo, 2010). 


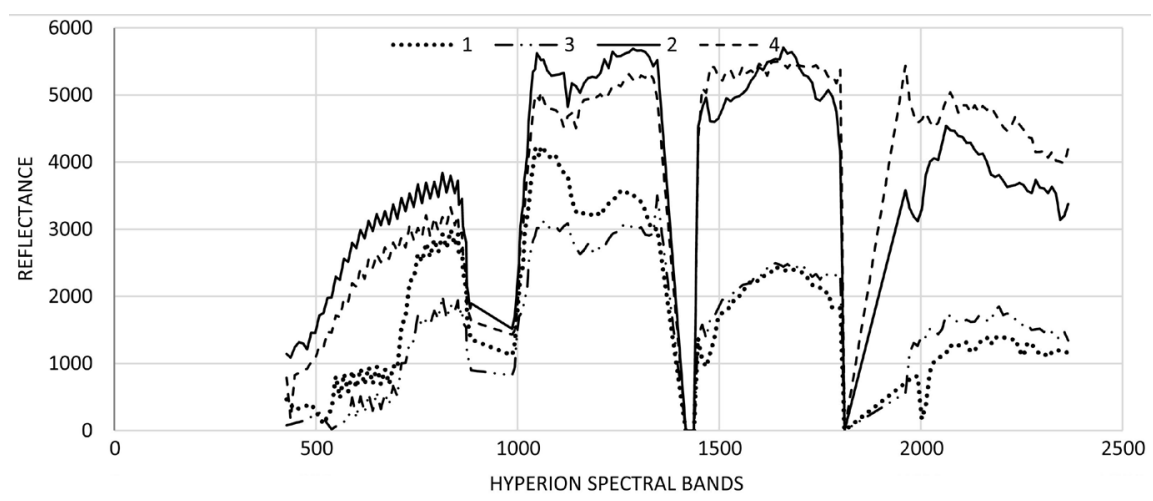

Figure 6. Spectral signature variation of different soil surface features due to differences in electrical conductivity: (1) $\mathrm{EC}=24.9 \mathrm{dS} \cdot \mathrm{m}^{-1}$; (2) $\mathrm{EC}=4.98 \mathrm{dS} \cdot \mathrm{m}^{-1}$; (3) $\mathrm{EC}=9.37$ $\mathrm{dS} \cdot \mathrm{m}^{-1} ;(4) \mathrm{EC}=0.184 \mathrm{dS} \cdot \mathrm{m}^{-1}$.

\subsection{Remote Detection of Soil Salinity from Spectral Indices}

The generated abundance maps presented in Figure 7 show the fractional amount of material present at each pixel. The three abundance maps (e.g. soil, urbanism and vegetation) were generated through the application of the LSU method. These maps show the spatial density distribution of the main three components composing the investigated region. The soil abundance map shows the predominance of bare soil in the study area. The vegetation abundance map reveals a high vegetation density to the north-east where the Oasis is found. The urbanism abundance map from the LSU method was helpful to delineate areas where was the man-made structures, so samples from this area were avoided when building the MLR relationship.

In this study, we decided to work with pixel's samplings that contain more than $50 \%$ soil. We eliminated every single sample located in a pixel containing less than $50 \%$ soil and we ended up with 32 samples.

The Hyperion images the earth's surface in 240 contiguous spectral bands which six of them (B7: Blue; B14: Green; B24: Red; B42: Infrared; B117: SWIR1; B162: SWIR2) were considered as indices of soil salinity. A Pearson correlation between the electrical conductivity values and the Hyperion spectral bands was conducted to evaluate which spectrum interval could reveal more about the salt-affected area.

According to Figure 8, among the Hyperion spectral bands, the blue band gives the highest correlation $(\mathrm{r}=0.31)$. The use of LSU improves the correlation within most of the applied remote sensing indices on the Hyperion data. There is a clear improvement in blue band where the correlation increases by $25 \%$. Nevertheless, band SWIR1 showed a weaker correlation after LSU.

Intensity indices show low correlation with the EC, varying between 0.13 and 0.14 even after the improvement generated by the LSU. Hence, the three intensity indices used in this study do not show potential for discriminating salt-affected soil. When correlating the performed salinity indices and the EC of the soil samples, salinity index 11 (SI11) and ASTER_SI provide the highest correlation, not only among the salinity indices but among all the spectral indices 

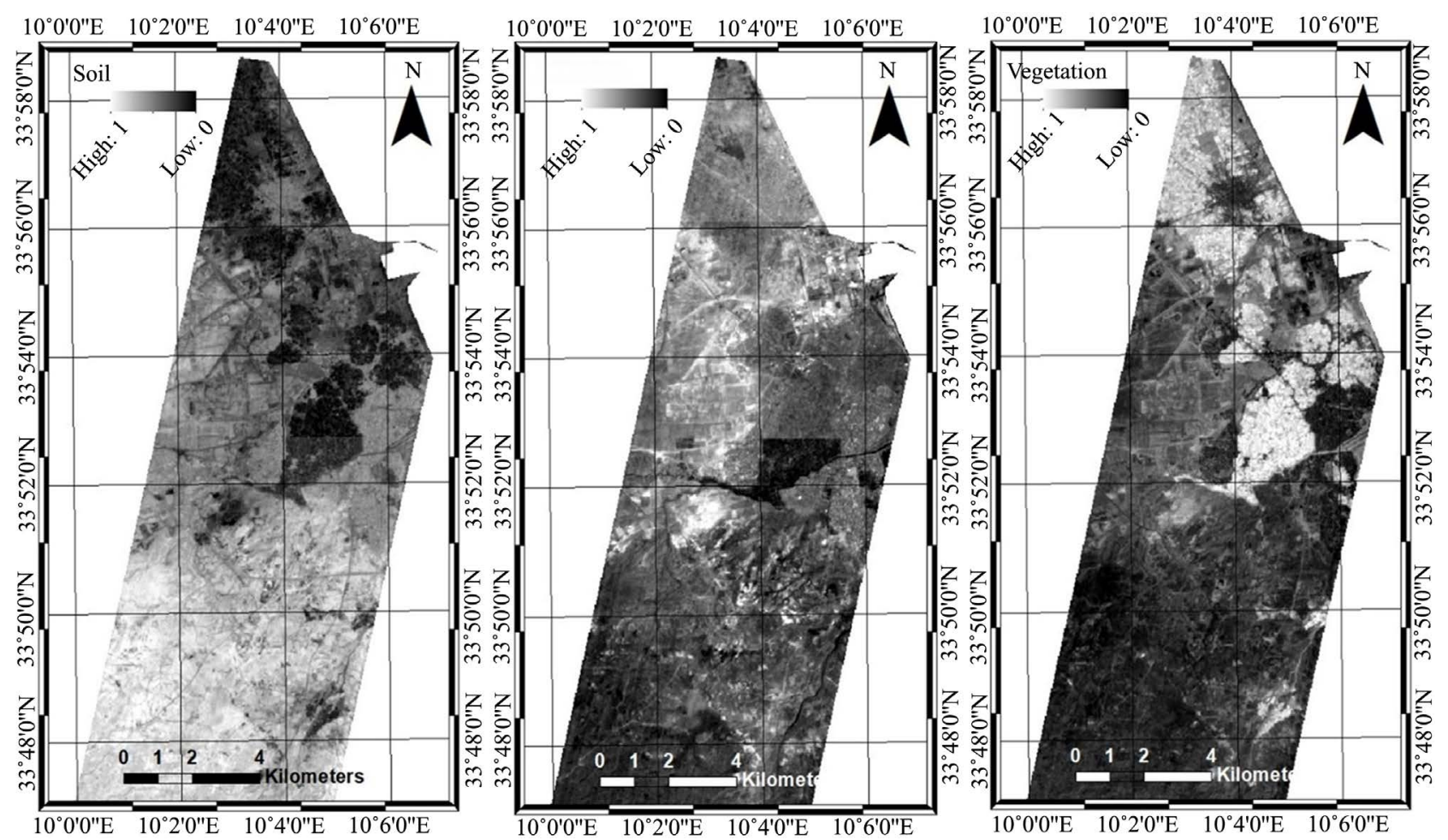

Figure 7. Grey scale abundance maps for soil, urbanism, and vegetation.

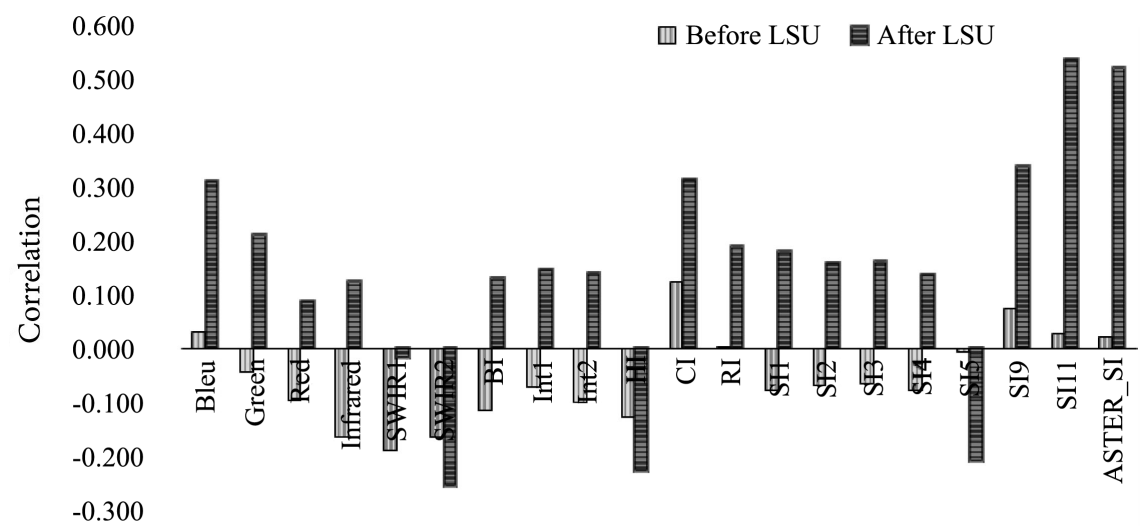

Spectral indices

Figure 8. Histogram showing the correlation values of EC and spectral indices before and after LSU.

performed in our work. SI11 and ASTER_SI are among a cluster of salinity indices where only the SWIR1 and SWIR2 are combined. These indices show the highest correlation compared to other indices where the VNIR bands are used. This is due to the high performance of SWIR1 and SWIR2 bands in retrieving patterns and features of soil salinity in the investigated area. The Hyperion VNIR bands showed a low correlation with EC; therefore, the salinity indices computed from these bands have a limited potential for detecting soil salinity. The low spatial resolution of the Hyperion data is one of the main reasons for such a weak correlation. Furthermore, the collected samples cannot be com- 
pletely representative of the pixels because the sample represents only one point on the relevant $30 \times 30 \mathrm{~m}$ pixel.

\subsection{Multiple Linear Regression to Predict Salt-Affected Areas}

A multiple linear regression model was applied to estimate the EC spatial distribution and predict salt-affected areas. Multiple linear regression (MLR) generates an equation where one or more independent variables (spectral indices that have the best correlation) is combined with estimated coefficients of the linear equation to finally predict the dependent variable which is EC.

The model is based on the data of the spectral salinity indices which gave the best correlation (as predictor variable) and the EC from ground truth measurements (as response variable). The best MLR approach found involves a combination of the salinity predictors SI11and ASTER_SI and was used to model the empirical relationship between electrical conductivity (EC) and soil salinity as showed by spectral indices. To create the MLR relationship, $80 \%$ of the samples were selected randomly by the software. The remaining samples were used for validation. The choice of the best model was based on the coefficient of multiple determination $\left(\mathrm{R}^{2}\right)$ computed by the model ([40] [41]).

The best $\mathrm{R}^{2}$ value in the regression output indicates that only $58 \%$ of the total variation of the predicted EC values can be explained by the predictor variables used in this model as shown in Figure 9.

The regression empirical relationship is given by the following formula:

$$
\text { Predicted EC }=-1142.507+1177.782 \times \text { SI11 }-2947.849 \times \text { ASTER_SI }
$$

The Equation (1) shows the best MLR empirical relation which is based on the spectral indices SI11 and ASTER_SI. These two indices show the highest and the best correlation with the EC from the ground truth. Combining these salinity indices helps to create a more reliable MLR empirical relationship to predict the salinity in soil. The standard error (also known as the root mean square error) of the estimate is the square root of the residual mean square.

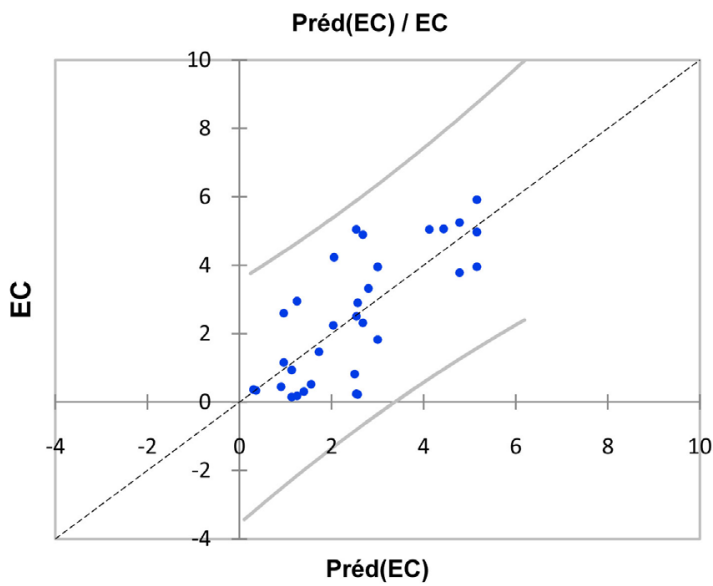

Figure 9. Relationship between measured and estimated electrical conductivity (EC) values (linear regression). 
Predicted values of electrical conductivity at the points representing salinity range of healthy soils, are often higher than the values from the ground truth measurements as shown in Figure 9.

The standard deviation of the data is about $1.57 \mathrm{mS} / \mathrm{cm}$ that's because the empirical relationship between measured and estimated EC values revealed an overestimation of the predicted electrical conductivity values. This slight overestimation found in the low values of electrical conductivity can be explained by the interference between salinity propriety and other soil proprieties which disturb the prediction. However, for samples with high electrical conductivity taken often from Sebkha, the main factor controlling the shape of the spectrum is the salinity propriety, which explains the decreasing of the RMSE values with the increasing of the electrical conductivity.

\section{Conclusions}

This study focused on the potential of LSU technique combined with remote sensing indices extracted from Hyperion data in improving the detection of salt affected areas in Ghannouch, Gabes. The results showed that the correlations improve in a remarkable way after applying the LSU method even if they remain moderate. This suggests that LSU technique has an important role in recovering more exact information regarding soil salinity.

A moderate coefficient of multiple determination $\left(\mathrm{R}^{2}=0.58\right)$ was found after applying the multiple linear regression model which makes it suitable for soil salinity assessment in the study area. However, several factors and/or indicators of soil salinization such as impact of land use land cover change, climate parameters, specie abundance, anthropogenic activities among others, coupled with the use of moderate to high resolution satellite imagery and an improved geostatistical model are needed in order to improve the results of the study for management strategies and early warning measures in the future.

\section{Acknowledgements}

The authors acknowledge the support of the Deutsche Akademische Austauschdienst (DAAD) to conduct this study.

\section{Conflicts of Interest}

The authors declare no conflicts of interest regarding the publication of this paper.

\section{References}

[1] Allbed, A. and Kumar, L. (2013) Soil Salinity Mapping and Monitoring in Arid and Semi-Arid Regions Using Remote Sensing Technology: A Review. Advances in Remote Sensing, 2, 373-385. https://doi.org/10.4236/ars.2013.24040

[2] Gorji, T., Tanik, A. and Sertel, E. (2015) Soil Salinity Prediction, Monitoring and Mapping Using Modern Technologies. Procedia Earth and Planetary Science, 15, 
507-512. https://doi.org/10.1016/j.proeps.2015.08.062

[3] Reza, S.O. (2017) Surface Soil Salinity Detection and Mapping, Using Hyperspectral Satellite Data of Hyperion Eo-1. Saussurea, 7, 32-44.

[4] Gorji, T., Yildirim, A., Sertel, E. and Tanik, A. (2019) Remote Sensing Approaches and Mapping Methods for Monitoring Soil Salinity under Different Climate Regimes. International Journal of Environment and Geoinformatics (IJEGEO), 6, 33-49. https://doi.org/10.30897/ijegeo.500452

[5] Abuelgasim, A. and Ammad, R. (2019) Mapping Soil Salinity in Arid and Semi-Arid Region Using Landsat 8 OLI Satellite Data. Remote Sensing Applications: Society and Environment, 13, 415-425. https://doi.org/10.1016/j.rsase.2018.12.010

[6] Zalacin, D., Silvia, M., Ramon, B., Andres, G. and Antonio, S. (2019) Salt Accumulation in Soils and Plant under Reclaimed Water Irrigation in Urban Parks of Madrid (Spain). Agricultural Water Management, 213, 468-476. https://doi.org/10.1016/j.agwat.2018.10.031

[7] Zaman, M., Shahid, S.A. and Heng, L. (2018) Irrigation System and Zones of Salinity Development. In: Guideline for Salinity Assessment, Mitigation and Adaptation Using Nuclear and Related Techniques, Springer, Cham, 105.

https://doi.org/10.1007/978-3-319-96190-3

[8] Liu, X., Feike, T., Chen, S., Shao, L., Sun, H. and Zhang, X. (2016) Effects of Saline Irrigation on Soil Salt Accumulation and Grain Yield in the Winter Wheat-Summer Maize Double Cropping System in the Low Plain of North China. Journal of Integrative Agriculture, 15, 2886-2898. https://doi.org/10.1016/S2095-3119(15)61328-4

[9] George, JK. and Kumar, S. (2015) Hyperspectral Remote Sensing in Characterizing Soil Salinity Severity using SVM Technique-A Case Study of Alluvial Plains. International Journal of Advanced Remote Sensing and GIS, 4, 1344-1360. https://doi.org/10.23953/cloud.ijarsg.122

[10] Saleh, A.M. (2017) Hyperspectral Remote Sensing in Characterizing Soil Salinity Severity Using SVM Technique: A Case Study of Iraqi Alluvial Plain, 2017. The Journal of American Science, 13, 47-64.

[11] Li, Y., Li, J. and Wen, J. (2017) Drip Irrigation with Sewage Effluent Increased Salt Accumulation in Soil, Depressed Sap Flow, and Increased Yield of Tomato. Irrigation and Drainage, 66, 711-722. https://doi.org/10.1002/ird.2132

[12] Feng, D., Zhang, J., Cao, C., Sun, J., Shao, L., Li, F., Dang, H. and Sun, C. (2015) Soil Salt Accumulation and Crop Yield under Long Term Irrigation with Saline Water. Journal of Irrigation and Drainage Engineering, 141, 04015025-1-7. https://doi.org/10.1061/(ASCE)IR.1943-4774.0000924

[13] Shabbir, A.S. (2013) Irrigation Induced Soil Salinity under Different Irrigation Systems: Assessment and Management, Short Technical Note. Climate Change Outlook and Adaptation: An International Journal, 1, 19-24.

[14] Sakadevan, K. and Nguyen, M. (2010) Extent, Impact and Response to Soil and Water Salinity in Arid and Semi-Arid Regions. Advances in Agronomy, 109, 55-74. https://doi.org/10.1016/B978-0-12-385040-9.00002-5

[15] Vengosh, A. (2003) Salinization and Saline Environments. Treatise on Geochemistry, 9, 1-35. https://doi.org/10.1016/B0-08-043751-6/09051-4

[16] Ghassemi, F., Jakeman, A.J. and Nix, H.A. (1995) Salinisation of Land and Water Resources: Human Causes, Extent, Management and Case Studies. CAB International, Wallingford, 544. 
[17] Metternicht, G.I. and Zinck, J.A. (2003) Remote Sensing of Soil Salinity: Potentials and Constraints. Remote Sensing of Environment, 85, 1-20. https://doi.org/10.1016/S0034-4257(02)00188-8

[18] Antipolis, S. (2003) Les menaces sur les sols dans les pays mediterraneens. Plan bleu, 80.

[19] Fourati, T.H., Bouaziz, M., Benzina, M. and Bouaziz, S. (2015) Modeling of Soil Salinity within a Semi-Arid Region Using Spectral Analysis. Arabian Journal of Geosciences, 8, 11175-11182. https://doi.org/10.1007/s12517-015-2004-3

[20] Bouksila, F., Bahri, A., Berndtsson, R., Persson, M., Rozema, J. and Van der Zee, S.E. (2013) Assessment of Soil Salinization Risks under Irrigation with Brackish Water in Semiarid Tunisia. Environmental and Experimental Botany, 92, 176-185. https://doi.org/10.1016/j.envexpbot.2012.06.002

[21] Louati, D., Majdoub, R., Rigane, H., et al. (2018) Effects of Irrigating with Saline Water on Soil Salinization (Eastern Tunisia). Arab Journal for Science and Engineering, 43, 3793-3805. https://doi.org/10.1007/s13369-018-3215-1

[22] Hachicha, M. and Aissa, I.B. (2014) Managing Salinity in Tunisia Oases. Journal of Life Science, 8, 775-782. https://doi.org/10.17265/1934-7391/2014.09.007

[23] Boulbaba, A., Marzouk, L., Rabah, R. and Najet, S. (2012) Variations of Natural Soil Salinity in an Arid Environment Using Underground Watertable Effects on Salinization of Soils in Irrigated Perimeters in South Tunisia. International Journal of Geosciences, 3, 1040-1047. https://doi.org/10.4236/ijg.2012.35105

[24] Wang, J., Ding, J., Abulimiti, A. and Cai, L. (2018) Quantitative Estimation of Soil Salinity by Means of Different Modeling Methods and Visible-Near Infrared (VIS-NIR) Spectroscopy, Ebinur Lake Wetland, Northwest China. Peer), 6, e4703. https://doi.org/10.7717/peerj.4703

[25] Raheem, M.A. and Hatem, A.J. (2019) Calculation of Salinity and Soil Moisture Indices in South of Iraq-Using Satellite Image Data. Energy Procedia, 157, 228-233. https://doi.org/10.1016/j.egypro.2018.11.185

[26] Bishop, T.F.A. and McBratney, A.B. (2001) A Comparison of Prediction Methods for the Creation of Field-Extent Soil Property Maps. Geoderma, 103, 149-160. https://doi.org/10.1016/S0016-7061(01)00074-X

[27] Bouaziz, M., Matschullat, J. and Gloaguen, R. (2011) Improved Remote Sensing Detection of Soil Salinity from a Semi-Arid Climate in NE Brazil. Comptes Rendus Geoscience, 343, 795-803. https://doi.org/10.1016/j.crte.2011.09.003

[28] Carré, F. and Girard, M.C. (2002) Quantitative Mapping of Soil Types Based on Regression Kriging of Taxonomic Distances with Landform and Land Cover Attributes. Geoderma, 110, 241-263. https://doi.org/10.1016/S0016-7061(02)00233-1

[29] Nawar, S., Buddenbaum, H. and Hill, J. (2015) Digital Mapping of Soil Properties Using Multivariate Statistical Analysis and ASTER Data in an Arid Region. Remote Sensing, 7, 1181-1205. https://doi.org/10.3390/rs70201181

[30] Ghosh, G., Kumar, S. and Saha, S.K. (2012) Hyperspectral Satellite Data in Mapping Salt-Affected Soils Using Linear Spectral Unmixing Analysis. Journal of the Indian Society of Remote Sensing, 40, 129-136. https://doi.org/10.1007/s12524-011-0143-x

[31] Masoud, A.A., Koike, K., Atwia, M.G., El-Horiny, M. and Gemail, K.S. (2019) Mapping Soil Salinity Using Spectral Mixture Analysis of Landsat 8 OLI Images to Identify Factors Influencing Salinization in an Arid Region. International Journal of Applied Earth Observation and Geoinformation, 83, Article ID: 101944. https://doi.org/10.1016/j.jag.2019.101944 
[32] Bouaziz, M.S. (2010) Identification et Caracterisation Hydrogeologique Et Geochimique De La Nappe Du Turonien Dans Le Sud Tunisien et Sa Relation Avec Les Aquiferes Adjacents. Doctoral Dissertation, Université de Sfax.

[33] Jemai, S., Ellouze, M. and Abida, H. (2017) Variability of Precipitation in Arid Climates Using the Wavelet Approach: Case Study of Watershed of Gabes in South-East Tunisia. Atmosphere, 8, 178. https://doi.org/10.3390/atmos8090178

[34] Szabolcs, I. (1989) Salt Affected Soils. CRC Press, Boca Raton.

[35] Chen, Y., Zhao, X. and Jia (2015) Spectral-Spatial Classification of Hyperspectral Data Based on Deep Belief Network. IEEE Journal of Selected Topics in Applied Earth Observations and Remote Sensing, 8, 2381-2392. https://doi.org/10.1109/JSTARS.2015.2388577

[36] Bioucas-Dias, J.M., Plaza, A., Dobigeon, N., Parente, M., Du, Q., Gader, P. and Chanussot, J. (2012) Hyperspectral Unmixing Overview: Geometrical, Statistical, and Sparse Regression-Based Approaches. IEEE Journal of Selected Topics in Applied Earth Observations and Remote Sensing, 5, 354-379. https://doi.org/10.1109/JSTARS.2012.2194696

[37] Bouaziz, M., Wijaya, A. and Gloaguen, R. (2011) Remote Gully Erosion Mapping Using ASTER Data and Geomorphologic Analysis in the Main Ethiopian Rift. Geo-Spatial Information Science, 14, 246-254. https://doi.org/10.1007/s11806-011-0565-1

[38] Psomas, A., Kneubühler, M., Huber, S., Itten, K. and Zimmermann, N.E. (2011) Hyperspectral Remote Sensing for Estimating Aboveground Biomass and for Exploring Species Richness Patterns of Grassland Habitats. International Journal of Remote Sensing, 32, 9007-9031. https://doi.org/10.1080/01431161.2010.532172

[39] Heinz, D.C. (2001) Fully Constrained Least Squares Linear Spectral Mixture Analysis Method for Material Quantification in Hyperspectral Imagery. IEEE Transactions on Geoscience and Remote Sensing, 39, 529-545. https://doi.org/10.1109/36.911111

[40] Draper, N.R. and Smith, H. (1998) Applied Regression Analysis. Third Edition, John Wiley \& Sons, Inc., Hoboken. https://doi.org/10.1002/9781118625590

[41] Wijaya, A., Liesenberg, V. and Gloaguen, R. (2010) Retrieval of Forest Attributes in Complex Successional Forests of Central Indonesia: Modeling and Estimation of Bi-Temporal Data. Forest Ecology and Management, 259, 2315-2326.

https://doi.org/10.1016/j.foreco.2010.03.004 